\title{
Scotland's liquor licensing changes: an assessment
}

\author{
JOHN C DUFFY, MARTIN A PLANT
}

\begin{abstract}
The impact of the changes in Scotland's liquor licensing laws was assessed by comparing trends in alcohol related problems in Scotland with those in England and Wales. The study showed no appreciable effect on the level of alcohol related morbidity and mortality, though some improvements were noted in relation to the rates of convictions for drunkenness. The changes introduced since 1976 appeared to be popular and there was widespread perception that public drunkenness had become less commonplace.
\end{abstract}

\section{Introduction}

Liquor licensing arrangements in Britain have been considered by two separate bodies-the Erroll committee, which related to England and Wales, ' and the Clayson committee, which related to Scotland. ${ }^{2}$ Both committees formulated a series of recommendations designed, it was hoped, to make bar room drinking more relaxed and socially integrated. The precise recommendations advanced by each committee differed, but both favoured extending the permitted hours of opening for public bars.

None of the proposals of the Erroll committee has so far been implemented. Scottish licensing arrangements, however, have been altered as a very limited response to the 60 changes suggested by the Clayson committee. Since December 1976 public bars have been allowed to remain open for an extra hour in the evenings. Before that date they were obliged to close at $10 \mathrm{pm}$. Subsequently public houses have been permitted to open on Sundays. This was previously possible only for bars situated in hotels and licensed clubs. In addition, some "all day licenses"-that is, regular extensions of permitted hours-have been issued by licensing courts, which were introduced during 1977.

The impact of these changes has been the subject of much debate. ${ }^{3.5}$ The importance of the Scottish reforms is currently heightened by a growing demand to introduce flexible bar opening hours in England and Wales. This review sets out to examine what evidence there is that the Scottish changes have had any impact on alcohol related problems. The implications of this evidence are considered in relation to options in social policy for the rest of Britain.

\section{Method}

Use and misuse of alcohol are influenced by many factors, ${ }^{6-8}$ and an assessment of the altered Scottish licensing laws requires more than a simple description of how alcohol misuse in Scotland has fluctuated since 1976. This review presents a comparison of the levels of officially recorded alcohol related problems in Scotland with those in England and Wales, where the "new" licensing arrangements do not apply. The comparison examines trends since 1970, six years before the first of the Scottish innovations was introduced.

Much of the following assessment is presented separately for men and women. This is because recent survey data produced by the Office of

Department of Psychiatry, University of Edinburgh, Edinburgh EH10 5HF JOHN C DUFFY, BSC, MSC, statistician, MRC unit for epidemiological studies in psychiatry, and lecturer, university department of statistics MARTIN A PLANT, MA, PHD, senior research fellow, alcohol research group Correspondence to: Mr Duffy.
Population Censuses and Surveys showed that although the alcohol consumption of Scottish men had remained relatively stable, that of women had risen considerably. ${ }^{9}$ The only variables presented here in which the sexes are not distinguished are drunkenness and drink-driving. Men hugely outnumber women on both counts. All of the data presented below have been plotted graphically on a logarithmic scale. This gives a better impression of the likely degree of random variation than would a linear scale. The Scottish population figures used in the analysis are mid-year estimates of the home population aged 15 or over by sex, based on the annual reports of the Registrar General for Scotland. ${ }^{10}$ The corresponding figures for England and Wales also relate to the home population aged 15 or over by sex. These were obtained from the Registrar General's reviews of England and Wales. ${ }^{11}$ This population base is used in figures 1 to 3 . Figures 4 and 5 use the estimated home population aged 15 or over for England only, obtained from the Mental Health In-patient Inquiry. ${ }^{12 \cdot 14}$

Mortality statistics for figures 1 to 3 were obtained from the annual reports of the Registrar General for Scotland ${ }^{10}$ the statistical reviews of the Registrar General, ${ }^{11}$ and the mortality by cause series compiled by the Office of Population Censuses and Surveys. ${ }^{15}$ Hospital admission statistics for figures 4 and 5 were obtained from Scottish Health Statistics ${ }^{16}{ }^{17}$ and the Mental Health In-patient Inquiry. ${ }^{12-14}$ Figures 4 and 5 are exceptional in that they relate to a comparison of Scotland with England only, and not England and Wales. This reflects the change in responsibility for the Welsh statistics from the Department of Health and Social Security to the Welsh Office during the 1970s. Statistics on drunkenness and drink-driving were obtained from Criminal Statistics, Scotland ${ }^{18}$ and from Criminal Statistics, England and Wales. ${ }^{19}$

\section{The evidence}

\section{MORTALITY FROM LIVER CIRRHOSIS}

Deaths from liver cirrhosis are an important indicator of alcohol misuse. ${ }^{20}{ }^{21}$ Between 1970 and 1978 such deaths were recorded under ICD (8th revision) code 571 as "cirrhosis of the liver." Since 1979 they have been classified in the ICD (9th revision) as "cirrhosis and chronic liver disease." Figure 1 shows the respective patterns of deaths from cirrhosis for men and women in Scotland and England and Wales. Figure 1 also shows the relative risks for Scottish men and women compared with their respective counterparts in England and Wales. All of these series showed an increasing trend. The risks in Scotland relative to England and Wales for both sexes had been rising, albeit very gently, since 1970 and did not appear to have been influenced by events during or since 1976 .

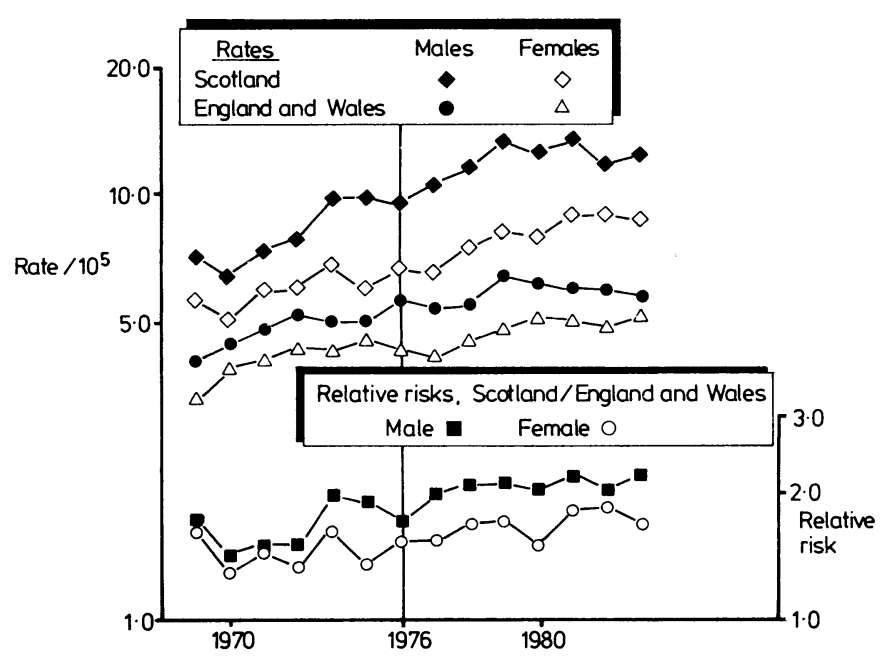

FIG 1-Mortality from liver cirrhosis. 


\section{MORTALITY DUE TO ALCOHOL DEPENDENCE}

Before 1978 deaths attributable to dependence on alcohol were classified in the ICD as due to "alcoholism" (303) and "alcoholic psychosis" (290). Since 1979 the former category has been replaced by "alcohol dependence." A serious difficulty obscures comparison of deaths from alcohol dependence in Scotland with those in England and Wales. South of the border a certification of alcohol dependence as cause of death led automatically (before June 1984) to the death being referred to the coroner. This may have discouraged doctors from attributing deaths to this cause. In Scotland alcohol related deaths are not normally subject to such further investigation.

Rates of mortality attributable to alcohol dependence have for some time been much higher in Scotland than in England and Wales (fig 2). Nevertheless, the general trends of mortality from alcohol dependence in Scotland have been very similar to those in England and Wales. During recent years they have been declining throughout Britain. The pattern of relative risks of mortality from alcohol dependence for men and women in Scotland was rather "noisy" or confused (fig 2). These risks had been increasing since 1972 , but again no particular anomaly or change seemed to have emerged since 1976. We emphasise that these rates relate to only small numbers of deaths.

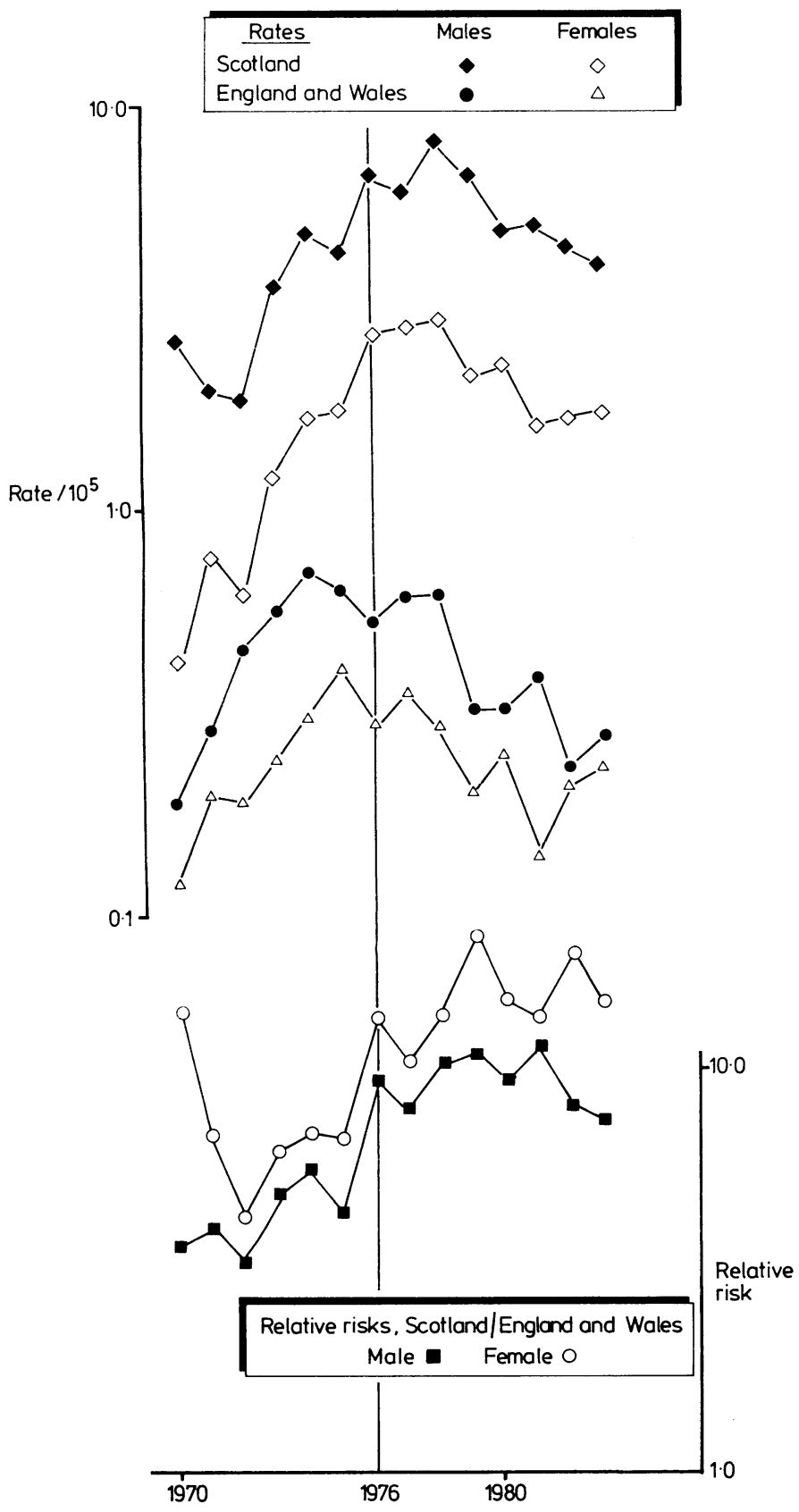

FIG 2-Mortality due to alcoholism (called alcohol dependence syndrome from 1979) and alcoholic psychosis.

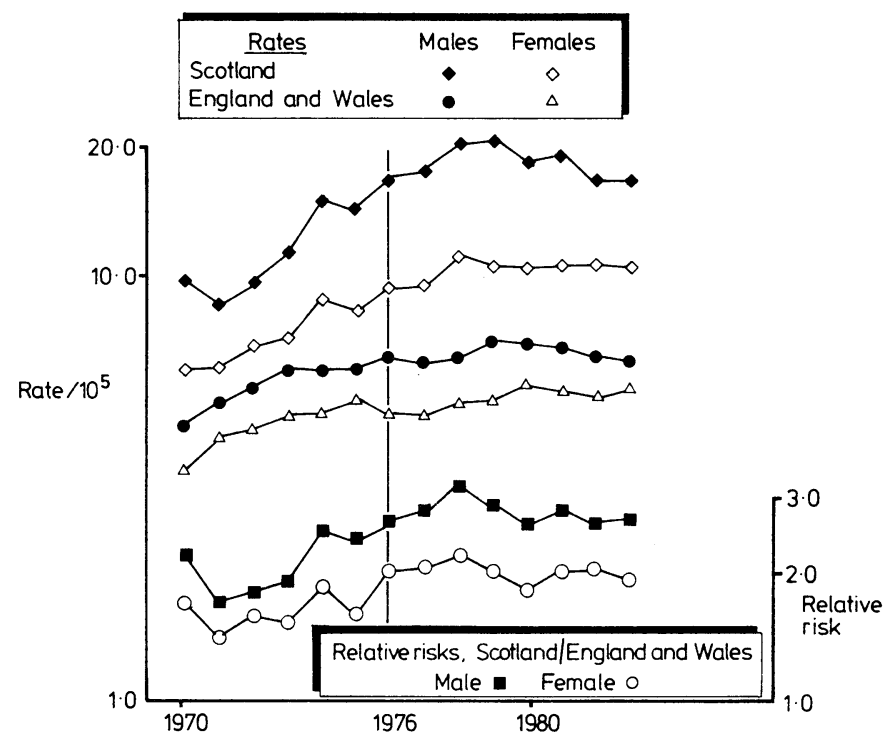

FIG 3-Total alcohol related mortality.

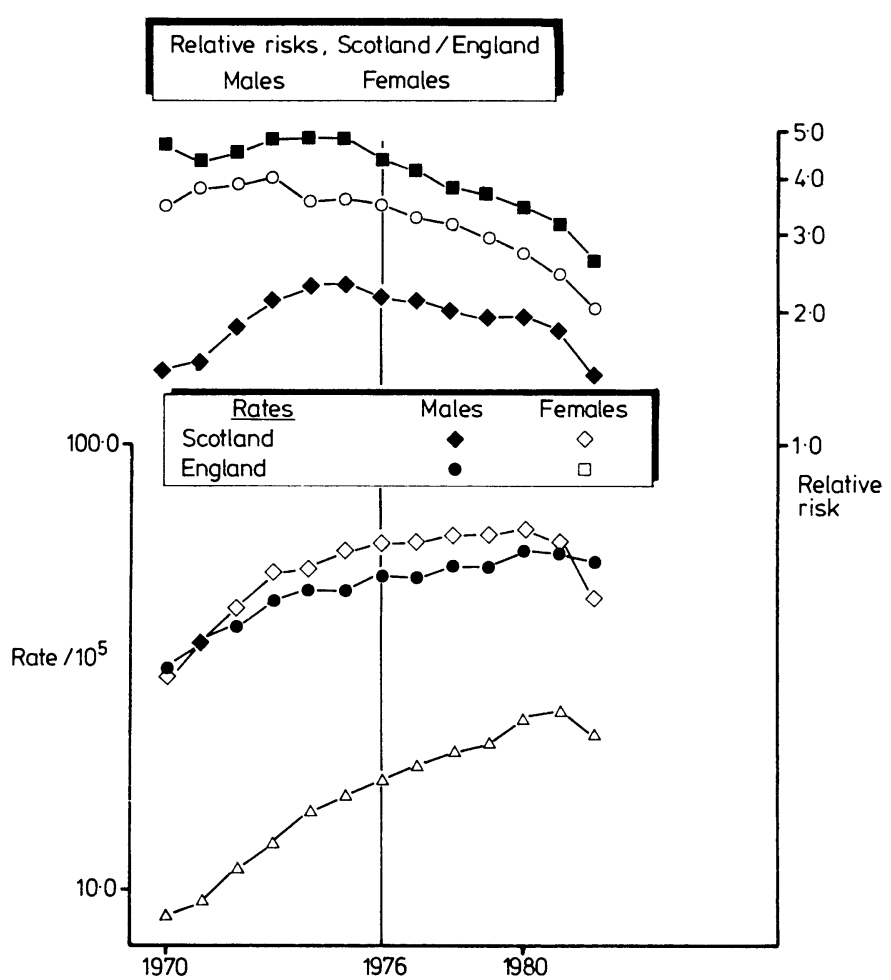

FIG 4-Psychiatric inpatient admissions for alcoholism/alcohol dependence and alcoholic psychosis.

\section{TOTAL ALCOHOL RELATED MORTALITY}

A more general impression was provided by combining deaths from liver cirrhosis, "alcoholism," and alcoholic psychosis (as defined above) with those attributed to alcohol poisoning (ICD E860). Figure 3 shows that the general trends were once more fairly uniform. The relative Scottish risks appeared to have increased until 1978 and then declined very slightly.

\section{HOSPITAL ADMISSIONS FOR ALCOHOL DEPENDENCE}

A second important indicator of alcohol misuse is the demand for services which provide help for problem drinkers. The several agencies available include Alcoholics Anonymous, councils on alcoholism, Drinkwatchers, as well as a wide range of other bodies. Admissions to psychiatric hospitals for 
alcohol dependence were considered since these relate to the whole of Britain throughout the period under review. We emphasise, however, that, while these are a useful indicator, they do not cover the full range of services now available for problem drinkers. Figure 4 shows the pattern of these psychiatric admissions.

The English data included in figure 4 are totals of admissions for "alcoholism" between 1970 and 1978. From 1979 these are totals of admissions for alcohol dependence and non-dependent abuse of alcohol. The data also include admissions for alcoholic psychosis. The Scottish figures before 1975 relate to "alcoholism" in general.

A clear downward trend was evident in the relative risks. This was particularly noticeable starting with the 1976 rates for Scottish men and after 1977 for Scottish women. The English rates had been increasing rapidly, whereas those among Scottish men declined in 1976 and continued to do so. Rates among Scottish women had fallen since 1980.

The rates of first admissions for alcohol dependence among Scottish men increased until 1974-5, then declined. The rates among Scottish women peaked in 1980. Among both men and women in England the rates increased steadily until 1980-1 (fig 5). The relative risks for both sexes in Scotland

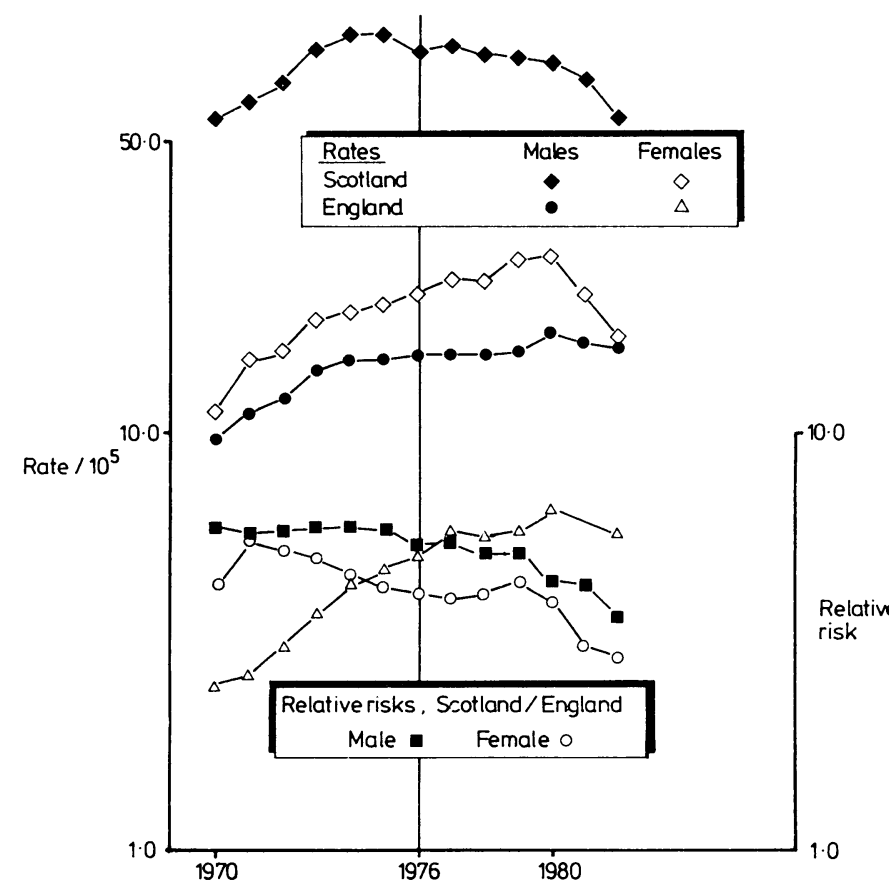

FIG 5-First admissions for alcoholism, alcohol dependence and alcoholic psychosis.

compared with England showed a downward trend. Even so, the Scottish risk of becoming a first admission for alcohol dependence remained more than three times higher for men and almost three times higher for women than in England. Alcohol dependence "rates" in Britain, however, reflect hospital admission policies and may give a severely distorted impression of the level of alcohol misuse in the community. ${ }^{22}$ In this review it is the trends which are relevant.

\section{PUBLIC ORDER OFFENCES}

Alcohol misuse is associated with a wide range of public order offences, ${ }^{23}$ and this review is confined to drink-driving and drunkenness. As noted by Kilich and Plant, the latter offence is defined differently in Scotland and England and Wales. ${ }^{24}$ Figure 6 shows the pattern of convictions for these offences since 1970 .

As noted above, the vast majority of convicted offenders are men. Figure 6 does not distinguish the sexes separately. Drink-driving convictions appear to have been relatively stable in Scotland, although the series showed a cyclic fluctuation which may reflect changing police policies. In England and Wales a strong upward trend was evident, which produced a noticeable reduction in the relative risk in Scotland.

Convictions for drunkenness in Scotland declined after 1975 and the rate of decrease accelerated, notably between 1980 and 1983. In contrast, figures for England and Wales showed an increasing trend. The relative risk series declined sharply from the peak in 1975, being less than one in 1982 and 1983. These patterns, though striking, may also be reflections not so much of the "scale of the problem" as of the policies implemented in relation to it. ${ }^{25}$

\section{OTHER EVIDENCE}

The Scottish Home and Health Department has been monitoring the effects of the alterations in the Scottish licensing law. An initial report by Knight and Wilson ${ }^{26}$ and a second report by the Office of Population

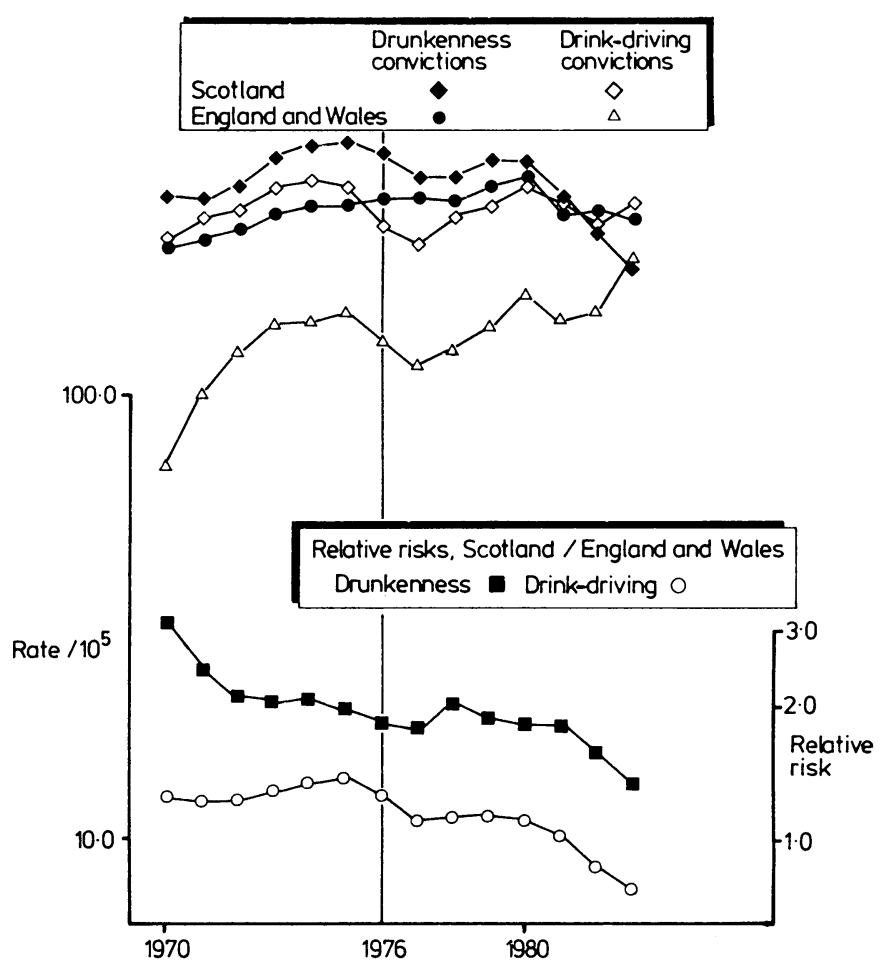

FIG 6-Convictions for drunkenness and drink-driving.

Censuses and Surveys ${ }^{9}$ presented the results of survey data collected from samples of people aged 18 and above in the four main cities and central belt of Scotland. Since neither study used a control group of people residing elsewhere in the United Kingdom, however, it is not possible to reach firm conclusions about the effects of the Scottish changes. Nevertheless, in both reports most of the respondents interviewed approved of the new licensing arrangements. The 1984 survey carried out by the Office of Population Censuses and Surveys found that $73 \%$ of respondents agreed with the statement that "The present licensing laws are an improvement on the old ones." Only $15 \%$ disagreed. In addition, $52 \%$ of respondents disagreed with the view that the new laws encouraged heavier drinking. Forty per cent agreed that the new law did have this effect. These views were reinforced by a majority assessment $(51 \%)$ that "These days you don't see as many drunks around as you used to." These and some of the other survey questions may fairly be criticised for not being worded in a properly impartial manner. They do, nevertheless, strongly suggest that more people in Scotland favour the new arrangements than are opposed to them. This is consistent with the earlier assessment by Knight and Wilson.

There are no separate general alcohol consumption data for Scotland. Several recent studies have suggested that alcohol consumption levels in Scotland are very similar to those elsewhere in Britain. Nevertheless, a higher proportion of Scottish alcohol consumption is in the form of spirits than is the case in England and Wales. In addition, alcohol consumption in Scotland appears to be slightly more concentrated-that is, occurs on fewer separate occasions-than in England and Wales. ${ }^{27}{ }^{28}$ Wilson suggested that Scottish alcohol consumption levels may once have exceeded those in England and Wales but that recently these differences may have faded. ${ }^{27}$

Kendell et al noted a small decrease in the alcohol consumption of a cohort of men in the Lothian region between 1978-9 and 1981-2. ${ }^{29}$ The Office of Population Censuses and Surveys concluded that between 1976 and 1984 
alcohol consumption among a sample of Scottish men remained virtually unchanged, while that among women rose by over a third. ${ }^{9}$ It is difficult to evaluate the implications of these studies in relation to the changed Scottish licensing arrangements since no directly comparable English and Welsh data are available. Alcohol consumption per head in the United Kingdom as a whole rose during the 1970s, reaching a peak in 1979. It has declined slightly since then.

\section{Conclusions and discussion}

Trends in alcohol related morbidity and mortality in Scotland compared with England and Wales did not show deleterious changes specifically related to 1976 , but appeared to be a continuation of the situation that was evident between 1970 and 1976 . Conversely, officially recorded rates for drunkenness have declined more in Scotland than they have in England and Wales. This evidence suggests that, in relation to health, the new Scottish licensing arrangements may be viewed neither as a cause of harm nor as a source of benefit. They have, in effect, been neutral. The reduction in the Scottish level of public order offences related to alcohol is encouraging. Even so, this may be due to a multiplicity of factors and is probably attributable more to changes in police policy than to the advent of a more relaxed or "civilised" style of drinking.

Throughout the period under review Scotland had a noticeably higher level of alcohol related problems than did the rest of Britain. The reasons for this are not entirely clear since several studies have suggested that both levels and patterns of Scottish alcohol consumption are similar to those in England and Wales. ${ }^{27} 28$

The main conclusion to be drawn from the evidence presented here is that the Clayson committee was correct in declaring in its report (p 13) that "Licensing, a negative and restrictive process, can play only a strictly limited part in the control of alcohol misuse."'

It is clear that the change in Scottish licensing laws has not had a dramatic effect. Despite this, two benefits are evident-the fall in public order offences, and the apparent popularity of the new arrangements. The facts reported here have been used selectively to support strongly opposing points of view. They will doubtless continue to be so. The Scottish experience does not appear to have been harmful. This, together with the benefits noted above, may be a reassuring omen in relation to the introduction of flexible opening hours for bars in England and Wales. It would be unwise to attempt to extrapolate from the Scottish experience to England and Wales in the event of licensing changes. It is also important to distinguish between "flexible" opening hours and extended opening hours. These are not necessarily synonymous. The evidence suggests that neither extreme benefit nor extreme harm would result from future changes.

We are indebted to Dr Norman Kreitman for comments on the initial version of this review.

\section{References}

1 Erroll of Hale. Report of the Departmental Committee on Liquor Licensing. London: HMSO, 1971. 2 Clayson C. Report of the Departmental Committee on Scottish Licensing Law. Edinburgh: HMSO, 1972

3 Saunders WM. Clayson: folly or foresight? In: McCrone D, ed. Scottish government yearbook. Edinburgh: University of Edinburgh, 1983:245-51.

4 Plant MA. Alcohol in Britain: patterns, problems, paradoxes and public policy. In: Single E, Storm T, eds. Public drinking and public policy. Toronto: Addiction Research Foundation (in press)

5 Allsop DT, Saunders WM. Drink, health and crime. The Times 1985 June 11:13 (cols 4-6).

6 Royal College of Psychiatrists. Alcohol and alcoholism. London: Tavistock, 1979:89-115.

Peck DF. Some determining factors. In: Plant MA, ed. Drinking and problem drinking. London: Junction, 1982:65-83.

8 Edwards G. The treatment of drinking problems. London: Grant McIntyre, 1982:13-22.

9 Office of Population Censuses and Surveys. Drinking and attitudes to licensing in Scotland. London: Government Statistical Service, 1985. (OPCS Monitor, 55 85/2.)

10 Registrar General for Scotland. Annual report of the Registrar General for Scotland. Part I, mortality statistics. Edinburgh: HMSO, 1971-85.

11 Registrar General. Registrar General's statistical review of England and Wales for the years 19701973. Part I, tables, medical. London: HMSO, 1971-5.

12 Department of Health and Social Security. Psychiatric hospitals and units in England and Wales. Inpatient statistics from the mental health inquiry for the year 1970. London: HMSO, 1972. (Statistical and Research Report Series, No 4 .)

13 Department of Health and Social Security. Psychiatric hospitals and units in England. In-patient statistics from the mental health inquiry for the year 1973. London: HMSO, 1976. (Statistical and Research Report Series, No 2.)

14 Department of Health and Social Security. In-patient statistics from the mental health inquiry for England for the years 1974-1983. London: HMSO, 1977-85. (Statistical and Research Report Series, No 17.)

15 Office of Population Censuses and Surveys. Mortality statistics. London: HMSO, 1977. (Series DH2, No 1.)

16 Scottish Home and Health Department. Scottish health statistics. Edinburgh: HMSO, 1971-4.

17 Scottish Health Service. Scoutish health statistics. Edinburgh: HMSO, 1975-85.

18 Scottish Home and Health Department. Criminal statistics, Scotland 1970-1983. Edinburgh: HMSO, 1977-84

19 Home Office. Criminal statistics, England and Wales, 1970-1983. London: HMSO, 1972-84.

20 Bruun K, Edwards G, Lumio M, et al. Alcohol control policies in public heulth perspective. Helsink Finnish Foundation for Alcohol Studies, 1975.

21 Davies P, Walsh D. Alcohol problems and alcohol control in Europe. London: Croom Helm, 1983.

22 Latcham RW, Kreitman N, Plant MA, Crawford A. Regional variations in British alcohol morbidity rates: a myth uncovered? I: clinical surveys. BrMed J 1984;289:1341-3.

23 Collins JJ Jr, ed. Drinking and crime. London: Tavistock, 1982.

24 Kilich S, Plant MA. Regional variations in levels of alcohol-related problems in Britain. $\mathrm{Br} \mathcal{J}$ Addict 1981;76:47-62. Erratum 1982;77:211.

25 Ross HL. Deterring the drinking driver. Lexington, Massachusetts: Lexington Books, 1984

26 Knight I, Wilson P. Scottish licensing laws. London: HMSO, 1980.

27 Wilson P. Drinking habits in the United Kingdom. Population trends. Winter. London: HMSO, 1982:14-8

28 Crawford A, Plant MA, Kreitman N, Latcham R. Regional variations in British alcohol morbidity rates: a myth uncovered? II: population surveys. $B r M e d ~ f$ 1984;289:1343-5.

29 Kendell RE, De Roumanie M, Ritson EB. Influence of an increase in excise duty on alcohol consumption and its adverse effects. Br Med f 1983;287:809-11.

(Accepted 5 September 1985)
What is the incidence of intestinal obstruction from peritoneal adhesions after an abdominal operation?

Like so many important questions about common problems, there is no accurate answer to this query. Most patients who have undergone laparotomy will have postoperative intra-abdominal adhesions. In my own study this amounted to about $90 \%$ of cases. Adhesions are almost certain to follow major surgery or where there have been multiple interventions. There is no way of estimating how many people have had a laparotomy; if this is one in every 25 of the population (probably a low estimate) this would mean that about two million people in the United Kingdom have adhesions. The vast majority of these are symptomless but if the patient is unlucky enough to have a loop of small bowel kinked, twisted by, or looped under an adhesive band then intestinal obstruction will result, and this may occur at any time from days up to many years after surgery. Certainly, adhesions are the commonest cause of intestinal obstruction in the Western world. ${ }^{1}$ Once again, however, there is no way of giving an accurate estimate of how often this emergency occurs. Adhesions are often blamed for chronic abdominal discomfort or other vague symptoms after abdominal surgery. One thing is certain, however, adhesions do not "grumble," they are either totally silent, in nearly everyone, or they produce, in a few, the unmistakable features of acute intestinal obstruction.- - HAROLD ELLIS, professor of surgery, London.
What is the most suitable way of rehydrating an adult stricken with diarrhoea and vomiting while travelling in a hot climate?

The dehydration accompanying minor episodes of diarrhoea in adults can usually be managed adequately by using salty food drinks such as Bovril (1 teaspoonful/cup) or soup, alternating with plain water ad lib. Soups containing starch (such as rice) aid sodium absorption. A more consistent result for more serious cases is achieved using a standard salt/sugar solution made from: one level teaspoon $(5 \mathrm{ml})$ of common salt, eight level teaspoonfuls of sugar, and one litre of water. Frequent sips should be taken in the initial stages to replace the existing deficit of 2-4 l over the first four to six hours. Thereafter, drinks should be taken every half to one hour, with an extra $300 \mathrm{ml}$ after every loose stool. In severe cases better results are obtained with special oral rehydration preparations such as sodium chloride and Dextrose Powder Compound BPC. This is available in convenient sachets (Dioralyte) sufficient to make up $200 \mathrm{ml}$ of solution. The new WHO/ UNICEF oral rehydration solution formula contains citrate in place of bicarbonate and is more stable. It also contains more sodium than the BPC preparation and is more suitable for correcting the severe electrolyte depletion that occurs in cholera.-DION R BELL, reader in tropical medicine, honorary consultant physician, Liverpool 